\title{
Saúde na televisão e a modernização do poder pastoral
}

\section{Health on television and the modernization of pastoral power}

\section{Salud en la televisión y la modernización del poder pastoral}

\author{
Marialice Nogueira Emboava | marialice.emboava@gmail.com \\ Pontifícia Universidade Católica de Minas. Belo Horizonte, Brasil. \\ Simone Maria Rocha | rochasimonemaria@gmail.com \\ Universidade Federal de Minas Gerais. Belo Horizonte, Brasil.
}

\section{Resumo}

Este artigo busca identificar como o discurso instituído do risco à saúde é construído no programa Bem Estar (TV Globo). Para tanto, apresenta-se a televisão como "analítica de governo", ou seja, como um recurso para adquirir e coordenar técnicas para gerir vários aspectos da vida do telespectador. Os conceitos de governamentalidade e tecnologia cultural embasam o estudo que mostra também como o poder pastoral atua na contemporaneidade. Utiliza-se a metodologia dos modos de endereçamento e se conclui que um dos modos de inserção do discurso no Bem Estar é instrucional: permeia todo o programa e pode despertar em alguns telespectadores o desejo e o prazer de aprender, como evidencia o quadro Aprendi com o Bem Estar.

Palavras-chave: saúde; televisão; governamentalidade; tecnologia cultural; poder pastoral. 


\begin{abstract}
This article aims to identify how the discourse of health risk is built into Bem Estar television show (TV Globo). For this purpose, television is presented as "an analytic of government", that is, as a resource for acquiring and coordinating techniques to manage different aspects of the viewer's life. The study that also shows how the pastoral power acts in the contemporaneity bases on the concepts of governmentality and cultural technology. The methodology used was one that approaches the forms of address and it is concluded that one of the forms of insertion of the discourse in the Bem Estar is the instructional one: it permeates the whole program and can awaken in some viewers the desire and pleasure to learn as evidenced by Aprendi com o Bem Estar.
\end{abstract}

Keywords: health; television; governmentality; cultural technology; pastoral power.

\title{
Resumen
}

Este artículo busca identificar cómo el discurso instituido del riesgo a la salud se construye en el programa Bem Estar (TV Globo). A fin de cumplir ese objetivo, se presenta la televisión como "analítica de gobierno", es decir, como un recurso para adquirir y coordinar técnicas para gestionar varios aspectos de la vida del espectador. Los conceptos gubernamentalidad y tecnología cultural fundamentan el estúdio que muestra también cómo el poder pastoral actúa en la contemporaneidad. La metodología utilizada fue aquella de los modos de direccionamiento y se há concluido que uno de los modos de inserción del discurso en el programa Bem Estar es el instruccional: atraviesa todo el programa y puede despiertar en algunos espectadores el deseo y el placer de aprender, como evidencia el quadro Aprendi com o Bem Estar.

Palabras clave: salud; televisión; gubernamentalidad; tecnología cultural; poder pastoral.

Contribuição dos autores: as autoras são igualmente responsáveis pelo texto.

Fontes de financiamento: CNPq.

Considerações éticas: não há.

Agradecimento/Contribuições adicionais: agradecemos ao CNPq o auxílio financeiro concedido.

Histórico do artigo: Submetido: 20.jun.2017 | Aceito: 22.set.2017 | Publicado: 29.dez.2017

Apresentação anterior: não houve.

Licença CC BY-NC atribuição não comercial. Com essa licença é permitido acessar, baixar (download), copiar, imprimir, compartilhar, reutilizar e distribuir os artigos, desde que para uso não comercial e com a citação da fonte, conferindo os devidos créditos de autoria e menção à Reciis. Nesses casos, nenhuma permissão é necessária por parte dos autores ou dos editores. 


\section{Introdução}

Cuidados com a dietética e com o corpo, tão propagados nos meios de comunicação massivos no mundo atual, é uma prática que remonta às asceses gregas clássicas. Diferenciam-se no tempo, como apontou Francisco Ortega ${ }^{1}$. Na antiguidade grega, era uma prática de liberdade. Integrava corpo e alma, remetia a valores comunitários e tratava de solidariedade política. Na contemporaneidade, a bioascese ${ }^{1}$ é individualista, relaciona-se a exercícios de adequação às normas e está submetida ao disciplinamento corporal. Embora distintas, evidenciam quão antigo é o desejo de cuidar de si - tema pelo qual o interesse da mídia parece não se arrefecer.

“As pessoas querem ler, ouvir e ver notícias sobre saúde. É um fenômeno mundial”, escreveu Roxana Tabakman $^{2}$ em livro dirigido a jornalistas e médicos. Ao ser indagada por dois repórteres do Portal Imprensa a respeito da proliferação de informações sobre saúde, a então diretora da revista Saúde da editora Abril, Lúcia Helena de Oliveira, não titubeou em apontar a oferta de informações diretamente proporcional ao aumento da demanda ${ }^{i}$. Ela lembrou que cuidar da saúde passou a ser in, é um valor associado à autoestima. Estariam as revistas, programas de rádio, televisão e sites apenas respondendo à demanda pela eterna busca de vivermos mais e melhor?

O valor-notícia de saúde cresce a cada dia e seus sentidos, produzidos e circulados na mídia, têm na televisão um meio importante por este ser um dos veículos pelos quais o brasileiro mais se informa sobre saúde $^{3}$. Nossos olhares voltaram-se para o Bem Estar, exibido diariamente, ao vivo, nas manhãs pela TV Globo. O programa parte da ideia de que o telespectador bem informado sobre os riscos à saúde mudará de comportamento e atitude se quiser longevidade e melhor qualidade de vida: maximiza-se o desejo de ser saudável ao aconselhar e guiar o indivíduo de maneira que ele possa perceber que deseja ser saudável.

O objetivo deste artigo é identificar como o discurso instituído do risco à saúde é construído no programa Bem Estar. Primeiro, argumentamos que o Bem Estar tem forte influência dos programas televisivos de estilo de vida ao contextualizá-lo em um panorama histórico sobre séries e programas de saúde. Em seguida, discutimos a televisão enquanto "analítica de governo", nos moldes defendidos por Laura Ouellette e James Hay ${ }^{4}$ em que a TV se torna um recurso para auxiliar o telespectador a gerenciar o seu dia a dia. Os conceitos de governamentalidade, poder pastoral e tecnologia cultural alicerçam esse caminho. Por fim, apresentamos modos de endereçamento como estratégia metodológica e analisamos o endereçamento instrucional do Bem Estar.

\section{Saúde na televisão brasileira}

No Brasil, o público geral e também os profissionais de saúde têm a televisão como uma das principais fontes de informação sobre saúde ${ }^{3}$ ainda que esta mídia comece a dividir a posição com a internet ${ }^{6}$. Nos anos 1970, encontramos programas voltados esporadicamente para esse assunto, como o Dercy de Verdade, que abordava temas gerais e outros do momento como a cura do câncer7. Nos anos 1980, abordar essa temática tornou-se mais frequente, pois foi a época em que a visão biologicista e higienista da saúde pública cedeu lugar para preocupações com estilo de vida, mais voltadas para doenças crônicas-degenerativas como câncer e diabetes ${ }^{8}$. O Globo Ciência, exibido a partir de 1984, foi o primeiro programa semanal regular de divulgação científica no Brasil e, convém lembrarmos, as descobertas da medicina e, portanto, os avanços ligados à saúde estavam atrelados ao jornalismo científico ${ }^{9}$. Nos primeiros dez anos do programa, o tema saúde foi o segundo mais veiculado ${ }^{10}$. Aos poucos, a saúde, que na década de 1970 havia se tornado um valor maior na sociedade norte-americana ${ }^{11}$, também se impõe no Brasil como tal, no final da década de $1990^{12}$.

Disponível em: http://portalimprensa.com.br/noticias/brasil/53984/ programas+na+tv+relacionados+a+saude+ampliam+o+repertorio+medico+da+populacao. Acesso em: 10 dez. 2016. 
Se verificarmos a ficção no Brasil e em outros países, observaremos que os seriados médicos fazem sucesso desde a década de 1950, quando a confiança no progresso científico era frequentemente associada à medicina - o que, em parte, até hoje se verifica. Séries norte-americanas como Dr. Kildare e Ben Casey despontaram. "As histórias abordavam doenças agudas ao invés de crônicas para que fosse possível um fim dramático, envolvendo situação de morte ou vida com a intervenção médica levando a uma recuperação final" ${ }^{13}$. Nos anos 1970, Medical Center ocupou o espaço dos programas médicos na televisão. Mas foi na década de 1990 que duas séries norte-americanas marcaram época: Chicago Hope, exibida entre 1996 e 2000, e ER (Emergency-Room), que foi ao ar entre 1994 e 2009. Essa última, até hoje, é transmitida por canais de TV a cabo e, entre 1995 e 1997, foi exibida pela TV Globo, com o nome de Plantão Médico ${ }^{\text {ii }}$. O sucesso no Brasil também foi marcante. Quando a TV Globo substituiu a série pelo programa Você Decide, fãs criaram o blog Alô Rede Globo queremos Plantão Médico de novo, numa época em que o uso da internet ainda não era tão disseminado.

Na metade da década de 1990, pesquisas de audiência já indicavam que o público visualizava, com mais frequência, jovens médicas ao invés de médicos ${ }^{13}$. Não é de se estranhar que a série Mulher ${ }^{\mathrm{ii}}$, exibida pela TV Globo durante 1998 e 1999, tivesse público cativo formado por homens, mulheres e adolescentes. Na esteira dos programas norte-americanos, a Globo criou essa série que tratava da vida das médicas Martha Correa Lopes (Eva Wilma) e Cristina Brandão (Patrícia Pilar) numa clínica privada do Rio de Janeiro. Sob a direção de Daniel Filho, a série dispunha da consultoria de um médico - assim como as norte-americanas para garantir verossimilhança à temática. A crítica televisiva não economizava elogios ao tratamento que a série dava a temas como aborto, estupro, Aids, violência doméstica, entre outros.

Tratados de forma sutil e com uma linguagem simples, de fácil acesso a qualquer tipo de telespectador [...]. Mulher é um programa de serviço, isto é, ele ensina como se prevenir contra a AIDS, a gravidez indesejada, as doenças venéreas etc., sem ser pouco atrativo como aquele insosso alerta contra o tabagismo [...] que vem logo após uma propaganda lindíssima de cigarro: O Ministério de Saúde adverte, fumar faz mal à saúde ${ }^{14}$.

O status do médico-herói já não é garantido na mídia, mas Clive Seale ${ }^{13}$ acredita que uma possível ameaça ao prestígio médico está muito longe de acontecer e que são mais frequentes as representações de médicos como tendo poderes (quase) mágicos. Que o diga o protagonista Dr. Gregory House, da série House, M.D., exibida pela Fox Network entre 2004 e 2012 e, na televisão aberta no Brasil, pela Record TV. Ele lidera uma equipe médica que, a cada episódio, tenta diagnosticar uma doença misteriosa nos pacientes. Dr. House, no entanto, não segue procedimentos médicos tradicionais, não obedece à política do hospital. Ele confia na sua inteligência e na sua habilidade para resolver problemas. "Analisando a série de maneira ampla, as super habilidades de House fariam dele o super-herói de que todos precisamos" ${ }^{15}$, afirma Mike Dubose, que defende que a série não é sobre procedimentos médicos, mas, sim, um programa de super-herói.

Na contemporaneidade, a ficção seriada sobre médicos, hospitais e correlatos convive com programas temáticos e canais de TV dedicados quase totalmente à saúde, como o Discovery Home \& Health, ou focados totalmente no tema, como o Canal Saúde (Fiocruz), uma emissora de televisão do SUS. Há também programas como Estilo e Saúde (Record News), Opção Saúde e Ser Saudável (TV Brasil), Bem Estar (TV Globo), além de quadros, por exemplo, no Hoje em Dia (Record TV) e no Fantástico (TV Globo). Todavia, tem se tornado cada vez mais evidente, desde o início do século XXI, que programas sobre saúde na televisão se alicerçam no surto do aconselhamento ${ }^{16}$ - oferecer conselhos na televisão não é novidade. O Programa de Saúde, veiculado entre 1987 e 1991 pela TV Cultura, por exemplo, já orientava mudanças de hábitos

Posteriormente, foi transmitida pelo SBT nos anos 2000. 
e cuidados com o corpo e a mente ${ }^{17}$. Essa forma antiga de aconselhar na televisão está ligada às revistas femininas, aos talk shows e também à cultura dos manuais de etiqueta que orientavam as mulheres ${ }^{18}$.

Nos últimos anos, no entanto, Tania Lewis ${ }^{18}$ observou a expansão dos programas que aconselham: eles ampliaram sua audiência incluindo o público masculino e passaram a ser exibidos em horário nobre em muitos países. É o surgimento de um subgênero da TV-realidade iiii. São os programas televisivos de estilo de vida, que abrangem uma variedade de formatos e cuja tarefa principal é a transformação e aperfeiçoamento da audiência ${ }^{20}$. Esse tipo de programa, produzido com pessoas comuns, com certa improvisação e relativamente barato pode ser visto como uma resposta ao cenário de desregulamentação do mercado de televisão nos anos 1980 e 1990, em que um sistema de multicanais emergiu e fez com que as emissoras disputassem fatias de audiência.

No entanto, somente as razões econômicas da indústria televisiva não explicam a proliferação desse subgênero televisivo. Vista na contemporaneidade como fenômeno global, a mídia de estilo de vida, que inclui revistas, rádio, web etc., tem sido investigada a partir das racionalidades liberais ${ }^{4,21,22}$ e a partir também da estética orientada para o consumo ${ }^{23-24}$. Neste caso, segundo Lisa Taylor ${ }^{24}$, os programas de estilo de vida ajudam a audiência a lidar com as mudanças sociais advindas da transição entre a cultura tradicional - em que os valores eram mais permanentes - e as novas formas sociais, que deixam muitos indivíduos inseguros. Analisar os programas televisivos de estilo de vida sob o viés da cultura de consumo significa, entre outros aspectos, atentar para o indivíduo enquanto sujeito em busca da sua identidade. Já a matriz das racionalidades liberais verifica como o indivíduo, em diferentes esferas da vida, é estimulado a ser um empreendedor de si mesmo, a maximizar o seu autogerenciamento.

À primeira vista, pensa-se em duas abordagens estanques, mas há pesquisadores ${ }^{4,21,25}$ que acreditam que o sujeito autogerenciado da televisão é interpelado mutuamente pelas forças interligadas do cidadão neoliberal e da estética orientada para o consumo. Para Binkley ${ }^{21}$, ambas estão relacionadas ao modo com que as pessoas vivem suas práticas diárias. Enquanto o projeto de identidade sob a perspectiva de estilo de vida mediado é configurado por meio de práticas essencialmente estéticas, derivadas de uma cultura de sedução de imagens e sensações, o polo complementar a essa prática decorre de terapeutas, conselheiros que incutem estilos de vida como técnicas racionais e, assim, projetam uma nova forma de subjetividade e poder social ${ }^{21}$.

Este artigo adota uma articulação entre essas duas abordagens dos programas televisivos de estilo de vida que influenciam o denominado Bem Estar e terminaram por renovar suas técnicas de reportagem ${ }^{\mathrm{iv}}$. Além da participação de pessoas comuns no estúdio, em geral para shows de dança, há os quadros de transformação, a maioria relacionada à perda de peso, mas em 2014 já foram veiculadas séries para ajudar crianças a dormirem a noite inteira; e, em 2013, a comerem melhor etc. Estamos diante da hibridização que caracteriza os programas televisivos. Jason Mittell ${ }^{26}$ se referiu a ela, valorizando as práticas da audiência: "A mistura de gêneros é um processo cultural ordenada pelo pessoal da indústria [televisiva], muitas vezes em resposta a práticas da audiência”. Misturar elementos de makeover show ou de game show a aspectos jornalísticos torna-se, assim, uma estratégia de comunicabilidade do Bem Estar para com os seus telespectadores. Porém, antes de mostrarmos como isso se dá no programa, abordaremos a televisão enquanto "analítica de governo".

\footnotetext{
iii TV-realidade é um gênero que inclui uma grande variedade de programas sobre pessoas reais. Também chamada de televisão popular factual, está localizada em território fronteiriço entre informação e entretenimento; documentário e drama ${ }^{19}$.

iv Em nossa pesquisa, categorizamos o programa como jornalismo de estilo de vida ${ }^{27}$.
} 


\section{A televisão como recurso para gerir o dia a dia}

Os pesquisadores Ouellette e Hay ${ }^{4}$ propõem pensar a televisão como "analítica de governo". Isso significa considerar, explicam eles, as formas múltiplas pelas quais os indivíduos e as populações são continuamente reinventados como cidadãos ativos e responsáveis. Significa também enfatizar a televisão como recurso para adquirir e coordenar técnicas de modo a gerenciar vários aspectos da vida. Os autores utilizam esse conceito na análise de programas da TV-realidade que, como observamos, é um termo amplo que inclui o subgênero programa televisivo de estilo de vida, que influencia o Bem Estar.

Ouellette e Hay se valem do conceito de governamentalidade, de Michel Foucault ${ }^{28}$, que se refere aos modos como o poder opera nas sociedades modernas. Para o filósofo francês, o poder emana do conhecimento especializado ou do conhecimento e procedimentos associados a instituições sociais - opera em rede, distribuído através de esferas de autoridade que administram habilidades, técnicas e tecnologias por meio de conselhos específicos. É um tipo de poder que se baseia em mecanismos difusos, como o discurso, incluindo aí não apenas os governamentais, mas também aqueles de instituições como a mídia. Colin Gordon ${ }^{29}$ explica que Foucault propôs uma definição para o termo governo em geral como "a condução da conduta".

Para Binkley ${ }^{21}$, os estudos atuais sobre governamentalidade revelam que a maneira de governar alicerçada na liberdade e autonomia de seus cidadãos vai além dos domínios das estruturas do Estado. As pesquisas passaram a considerar os diversos modos com que as racionalidades de governo são sugeridas de maneira sutil na vida diária: no domínio da política, da vida econômica, das responsabilidades familiares, por meio do discurso de autoridades e especialistas - o surgimento destes remonta ao século XIX, e eles criaram uma maneira de moldar e guiar os seres humanos para melhores estratégias de autorregulação que não estavam ligadas aos poderes estatais oficiais, segundo Nikolas Rose ${ }^{30}$. Este pesquisador afirma que profissionais de medicina, psiquiatria, assistentes sociais operaram (e operam) como tecnologias difusas de governo indireto tentando influenciar a conduta das pessoas e os hábitos em diversas arenas especializadas incluindo saúde, higiene, moralidade, recreação, arranjos domésticos etc.

Para a engrenagem dos experts funcionar, o liberalismo espera que os indivíduos participem da sua própria governança, e o conceito de poder pastoral e as técnicas de confissão, apontados por Foucault, auxiliam a entender o processo ${ }^{4}$. Foucault ${ }^{31}$ explica que a modernização do poder pastoral assegurou a salvação não mais no outro mundo, mas neste. A palavra salvação, neste contexto, possui diversos significados: saúde, bem-estar (isto é, riqueza suficiente, padrão de vida), segurança, proteção contra acidentes. Cresceram também o número e os tipos de poderes pastorais oficiais incluindo atores não estatais. $\mathrm{O}$ autor ${ }^{31}$ afirma que o poder se exerce por meio de empreendimentos privados, de filantropos, de maneira geral, e de instituições antigas, como a família. Também é exercido por estruturas complexas como a medicina e, neste caso, incluem tanto as iniciativas privadas (venda de serviço com base na economia de mercado) quanto também as instituições públicas (como os hospitais).

As técnicas do cristianismo de confessar, por sua vez, tornaram-se centrais não apenas para a organização dos poderes religiosos, mas também para a dos civis na medida em que o direito, a pedagogia, as relações pessoais e outros domínios também as incluíram como técnica de produção da verdade. "A confissão passou a ser, no Ocidente, uma das técnicas mais altamente valorizadas para produzir a verdade”33. Enquanto essas técnicas faziam com que os indivíduos trabalhassem sua própria mortificação neste mundo, o Estado liberal agiu no pastoralismo das instituições e atividades da sociedade civil para construir seu papel como provedor de bem-estar ${ }^{4}$. As técnicas usadas para observar indivíduos, desenvolvidas pelo cristianismo, foram também úteis para a racionalidade do governo liberal.

Aprofundamos o papel do especialista em Emboava e Rocha ${ }^{32}$. 
Ouellette e Hay ${ }^{4}$ explicam que é necessário identificar as racionalidades específicas e as aplicações técnicas que compõem a televisão e que elas são importantes de modo particular para pensá-la como analítica de governo. De acordo com esses autores,

Uma maneira [de identificar a racionalidade específica e as aplicações técnicas da televisão] é como uma tecnologia cultural que, trabalhando fora dos 'poderes públicos', governa ao apresentar indivíduos e populações como objetos de avaliação e intervenção, e solicitando a participação deles no cultivo de hábitos particulares, ética, comportamentos e habilidades4.

O fato de uma mídia popular atuar como tecnologia cultural no dia a dia não é novidade. Ouellette e Hay ${ }^{4}$ lembram que as revistas, por exemplo, há muito promovem saúde, conceito de famílias nucleares e outras agendas compartilhadas por governantes. No entanto, os programas de TV têm a vantagem, em relação a algumas mídias, da serialização e, muitas vezes, de exibição diária, facilmente acessada no espaço privado do lar, pois em geral a TV ocupa uma posição central no ritmo diário de uma casa. Há outro aspecto que os autores salientam: a intensidade com que programas televisivos têm adotado a gramática terapêutica da responsabilidade individual, do autoempoderamento e aplicado a uma grande gama de programas - desde a limpeza da casa à obesidade de filhos.

Pensar a televisão como tecnologia cultural implica em relacioná-la às artes e ciências do desenvolvimento (cultivation) $)^{4}$, apropriadas aqui como a arte de burilar costumes, atitudes. Os autores referem-se ao termo techné para expressar as qualidades da TV que vão além da técnica. Isto é, a televisão possui destreza com certas habilidades e aplicações presentes diariamente nas modulações de programas de TV-realidade sobre competição, demonstrações etc: a televisão opera no dia a dia, auxilia as demonstrações e lições de estilo de vida nos programas televisivos.

Outra dimensão da televisão enquanto tecnologia cultural refere-se ao autodesenvolvimento como um autoaperfeiçoamento, sendo a ênfase dos autores dada ao cuidado de si. Em geral, programas televisivos de estilo de vida dão orientações práticas para uso diário, e o telespectador coloca-as em teste no cotidiano. Este aspecto relaciona-se às tecnologias do self definidas por Foucault ${ }^{34}$ para descrever como a liberdade e o agenciamento de um indivíduo são conquistas técnicas que envolvem vigilância e trabalho que ele deve fazer de maneira particular em si mesmo. Dito de outra maneira, o neoliberalismo se esforça para assegurar que os indivíduos se autoaperfeiçoem e reúnam capital humano suficiente para se tornarem empreendedores de si35.

Ao pensarmos a televisão como tecnologia cultural, verificamos que o Bem Estar tenta moldar a conduta dos seus telespectadores, como mostraremos na próxima seção. Apresentado de segunda à sexta-feira por dois jornalistas e coapresentado por uma dupla não fixa de profissionais da saúde ${ }^{\text {vi }}$ o programa traz reportagens, quadros e perguntas dos telespectadores enviadas pela internet. As temáticas incluem um abrangente catálogo de assuntos - desde pólipos, cistos e nódulos a bronzeamento da pele e queda de cabelos; de dicas alimentares para emagrecer a técnicas invasivas como redução de estômago ou inserção de balão gástrico; de lesões na boca a ansiedade e depressão. Esta diversidade de assuntos indica que o programa adota o conceito ampliado de saúde, de Nikolas Rose ${ }^{36}$ : "o desejo de saúde não seria somente procurar evitar a doença ou a morte prematura, mas englobaria uma otimização da corporalidade de uma pessoa para abranger um estado global de bem-estar: beleza, sucesso, felicidade, sexualidade e muito mais".

vi Esporadicamente, apenas um profissional é da saúde. O outro pode ser da engenharia, química etc. 


\section{Endereçamento instrucional}

Para analisar o Bem Estar, utilizamos modos de endereçamento que, nascidos na análise fílmica, têm sido usados, desde o final dos anos 1970, para interpretar a maneira como os programas televisivos constroem sua relação com os telespectadores ${ }^{37-38}$. “O conceito de 'modo de endereçamento' designa as formas comunicativas específicas e práticas de um programa que constituem o que poderia ser referido na crítica literária como seu 'tom' ou 'estilo"”39 (aspas do original).

Assim, modos de endereçamento se referem ao estilo usado por um programa para se relacionar com a audiência de maneira que, ao mesmo tempo em que esse estilo confere identidade ao programa, também o diferencia dos demais. Não há operadores fixos para análise ${ }^{38}$, pois é a partir da assistência ao produto que o pesquisador decide quais elementos contribuem para a configuração de um determinado endereçamento ${ }^{\text {vii }}$. Utilizamos três operadores: aspectos formais, temáticas e mediadores. O corpus ${ }^{\text {vii }}$ de nove edições foi extraído de uma análise longitudinal em que foram examinados 60 programas entre fevereiro de 2011 (início do programa) e abril de 2016. Apresentamos aqui apenas um dos modos de endereçamento ao qual chegamos: o instrucionalix.

Os maestros da narrativa do Bem Estar são os jornalistas-apresentadores Mariana Ferrão e Fernando Rocha, que alinhavam e constroem unidade dos diversos sujeitos de fala: especialistas, repórteres e telespectadores - estes enviam perguntas pela internet e são posicionados como aprendizes. Para Yvana Fechine ${ }^{41}$, Ferrão e Rocha são a cara do programa que comandam e a credibilidade deste é influenciada diretamente pela confiança que os telespectadores depositam nos seus apresentadores - a carreira profissional também colabora para o grau de confiança que a audiência deposita neles ${ }^{38}$. Ambos chegaram ao Bem Estar sem terem vivenciado o estrelato se comparados, por exemplo, a Fátima Bernardes que comanda Encontro, programa que sucede ao Bem Estar nas manhãs da Globo. Mas eles não eram inexperientes . $^{x}$ Por vezes, são também personagens de quadros do Bem Estar, protagonizando o que alguns pesquisadores chamam de mídia em primeira pessoa (first person media), um jeito subjetivo, autobiográfico e confessional de se expressar ${ }^{20}$.

A credibilidade do programa não está a cargo totalmente dos jornalistas-apresentadores. Ela é compartilhada com os especialistas em saúde, os mestres do Bem Estar que, diariamente, dividem o estúdio com os apresentadores. Entre eles, há um corpo de consultores formado por nomes renomados da medicina, reforçando o prestígio social que esses profissionais desfrutam em nossa sociedade ${ }^{\mathrm{xi}}$.

O cenário tem uma sala que pode se transformar em espaço para representação de dança, luta, jogo ou se converter em quarto, banheiro ou área de serviço. O equipamento principal é uma bancada e, em comparação com a do telejornalismo - em que ela é o local que confere autoridade aos jornalistas para tratar de temas mais vinculados ao paradigma dominante do jornalismo ${ }^{42}-$, diríamos que é dali

\footnotetext{
vii Mediador, a voz do povo (Povo Fala), e a entrevista em profundidade podem ser usados como operadores de análise, segundo John Hartley ${ }^{40}$. Itania Gomes utilizou-os, acrescidos de outros quatro, em análise do Jornal do SBT. Anos depois, o grupo de pesquisa da UFBA, coordenado por ela, desenvolveu quatro operadores para análise do telejornalismo: mediador, contexto comunicativo, pacto sobre o papel do jornalismo e organização temática.

viii O corpus do presente artigo é constituído pelas seguintes edições: $\underline{01 / 04 / 2011} ; \underline{13 / 01 / 2012} ; \underline{29 / 08 / 2012} ; \underline{16 / 07 / 2013} ; \underline{05 / 02 / 2014}$; 19/05/2014; 02/02/2015 (1 e 2 ); 15/05/2015 (1, 2, 스); 13/11/2015.

ix Nesta pesquisa, trabalhamos também com o endereçamento do 'autocuidado' e do 'perigo sempre à espreita'.

x Mariana Ferrão fez carreira na TV Bandeirantes em que começou como repórter do tempo e chegou a cobrir a Copa do Mundo de 2006, os Jogos Pan-Americanos de 2007 e a dividir a bancada do Jornal da Band. Fernando Rocha é jornalista há mais de 18 anos da TV Globo, em que já atuou no jornalismo esportivo. Também tem formação como ator.

xi Na página do programa, estão arrolados como consultores o cardiologista Roberto Khalil; o ginecologista José Bento; a pediatra Ana Escobar; o psiquiatra Daniel Barros; o protologista Fabio Atui; a dermatologista Marcia Pucelli e o médico do esporte Gustavo Magliocca.
} 
que os especialistas exercem a autoridade máxima em saúde e estilo de vida ao ensinar para milhões de telespectadores-aprendizes seus poderes de verdade.

Há diferença entre a gordura abdominal do homem e da mulher? Na bancada do programa de 01/04/2011, o endocrinologista Márcio Mancini exemplifica as diferenças com gelatina amarela para a gordura e vermelha para os músculos. Elas estão em um recipiente transparente e o telespectador pode aprender algo que talvez já saiba, mas que provavelmente nunca havia visualizado: nos homens, a gordura se acumula na parte interna da barriga, entre os órgãos. É a gordura visceral, que pode ser vista graças às diferentes cores das gelatinas. Nas mulheres, a gordura é subcutânea, menos prejudicial e se acumula nas coxas e nos quadris antes da menopausa. As explicações prosseguem intercaladas por perguntas da jornalista Mariana.

Reconhecemos que ensinar e desvendar o funcionamento do corpo humano é parte essencial dos modos de o Bem Estar se endereçar à audiência. Demonstrações como essas presentificam o que muitos telespectadores compreendem, mas raramente veem. Elas são aparatos de aproximação com a audiência, pois à medida que revelam informações cria-se uma atmosfera na qual o telespectador é incluído porque ele pode ter a sensação de que está aprendendo algo. Alfredo Vizeu ${ }^{43}$ nomeia esses aparatos como operadores didáticos no telejornalismo. É possível aqui fazermos um paralelo com House M.D., em que tecnologias de visualização do corpo, diagnósticos computadorizados, monitoramento em tempo real etc. foram apontados como coatores da ficção ${ }^{44}$. Menos sofisticados e submetidos ao discurso verbal, os operadores didáticos do Bem Estar fazem parte da sua identidade, embasam seu estilo, e permitem a visualização de mecanismos e processos muitas vezes complexos, oferecendo-se à fruição fática e sensível do telespectador.

Convém lembrarmos que o aspecto educativo e de entretenimento permeia, em níveis diferentes, todo o programa, constituindo o que alguns autores chamam de edutainment ${ }^{45}$. Este aspecto surge na primeira década do século XXI configurado por tecnologia de som e imagem mais apurada que, associada a uma maneira mais descontraída de abordar a temática saúde, permite novos efeitos de significado. Mas está longe de ser um aspecto genuinamente novo, conforme já mencionamos. E como o aspecto educativo é reconfigurado no século XXI? Na contemporaneidade, os especialistas ganham a cena e se tornam referência central na vida de muitos indivíduos ${ }^{21,30,46,47}$. A televisão, por sua vez, desempenha um papel poderoso nessa mudança, pois articula perfeitamente a figura do especialista no espaço privatizado, doméstico e no imaginário coletivo das comunidades mediadas ${ }^{46}$.

A conversa amigável entre os apresentadores e especialistas é sempre ajudada pelo uso de metáforas. $\mathrm{Na}$ edição de 2/2/2015, um jogo de cartas exemplifica as "estações das desculpas" para uma pessoa parar de fazer uma dieta. É uma forma de apropriação que os produtores de o Bem Estar fazem do game show e que leva a nutricionista, ao retirar uma carta do jogo, a orientar quem não tem tempo de comer de três em três horas, como recomendam esses especialistas sobretudo para quem está de dieta:

Então, o planejamento em primeiro lugar. A gente tem de fazer uma organização da casa, ver o que a gente pode comprar para a semana para não perder alimento. Então algumas dicas. Será o planejamento com coisas que durem uma semana, sem estragar, e que você possa levar para o trabalho também. Por exemplo, deixar um lanchinho pronto, à noite, na geladeira e, no dia seguinte, colocá-lo no microondas por 30 segundos. Pronto. Quebrou o frio, ficou quentinho, come-se muito rápido e você quebrou o jejum com um lanchinho de queijo que seria bastante importante. Uma outra situação muita rápida para o café da manhã é ter iogurte, aveia e frutas secas. A gente pensou no iogurte porque fica no potinho, na geladeira, e é só colocar onde vai comer: numa taça, num copo ou numa xícara. Colocar um cereal saudável como a aveia e colocar frutas secas porque as in natura, muitas vezes, apodrecem; as pessoas perdem tudo, jogam fora. (Tânia, nutricionista, programa de $02 / 02 / 2015)^{x i i}$

\footnotetext{
xii As transcrições foram adaptadas para maior compreensão do leitor, excluindo-se vícios de fala e quaisquer elementos que prejudicassem a fluência do texto transcrito.
} 
É para os detalhes do dia a dia que a nutricionista se volta; é para o interior da casa do telespectador e da sua família, oferecendo uma narrativa instrucional sobre alimentação saudável e dieta. Oullette e Hay ${ }^{4}$ afirmam que os programas da TV-realidade, gênero que influencia o Bem Estar, são recursos acessíveis para gerenciar as tarefas banais do cotidiano e também as múltiplas dimensões de nossa vida pessoal. Assim, o Bem Estar oferece ao telespectador maneiras de governar o dia a dia, ligando conhecimento à capacidade de planejar o café matinal de maneira que o telespectador coma de forma saudável, sem desperdício de alimentos. Na edição selecionada, o Bem Estar não menciona nenhum aspecto socioeconômico de quem tem sobrepeso ou obesidade. O programa enquadra o emagrecimento e a alimentação saudável como questão de planejamento e de organização; como questão apenas de força de vontade do indivíduo, de escolha individual.

Isto nos remete ao conceito de healthism: é um sistema de crenças, cunhado por Robert Crawford ${ }^{11}$, que define as atividades de promoção da saúde como uma obrigação moral que pode ser conseguida por meio da adesão individual aos diversos protocolos de saúde. Esse tipo de discurso contribui para a formação de um sujeito que voluntariamente vai aderir a ações para melhorar a sua saúde, em que os especialistas e seus poderes de verdade podem conduzir a conduta do telespectador ${ }^{30,47}$, pois as enfermidades seriam decorrentes de comportamentos desinformados. O indivíduo, assim, desenvolve formas particulares de autodisciplina e autovigilância ${ }^{48}$. Crawford ${ }^{11}$ não questiona o valor terapêutico de se responsabilizar o indivíduo pela própria saúde, mas lembra que o healthism leva a concepções e estratégias não-políticas e, portanto, ineficazes de promoção da saúde.

\section{Saber consumir}

À primeira vista, em termos de consumo, o Bem Estar difere bastante, por exemplo, do Mais Você, programa que o antecede na Globo. A produção cuida para nem mostrar nem falar marcas de produtos alimentícios ou de remédios. Mesmo assim, o incentivo ao consumo existe. Menos aparente, ele é reconfigurado na forma de aquisição de conhecimento e os especialistas têm papel fundamental. O programa de 16/07/2013 exemplifica como uma telespectadora bem-informada é capaz de refletir antes de escolher qual sutiã comprar igualando esse ato ao de decidir, por exemplo, que alimentos consumir. Ascendido a um lugar vital na prática da vida diária, a escolha do sutiã se torna uma questão de identidade ${ }^{24-25}$. O assunto daquele programa foi a saúde dos seios: trataram de tipos de top e de sutiã, redução e também aumento de mamas, secreção dos seios fora do período de amamentação que pode ser um sinal de câncer etc. Entre esses assuntos, os tipos de sutiãs predominaram e a reportagem externa, de 6 min $54 \mathrm{~s}$, foi dividida em duas. Examinemos parte dela:

Esse é o sutiã certo para ela. Ela está usando sutiã 46, que é o tamanho dela, com a taça C que é o tamanho maior porporcionalmente. Então, o bacana é que ele tem as laterais mais largas e reduz essa gordurinha de que a gente não gosta [Consultora]. E a alça? [Marina, repórter]: A alça é mais larga. Então vai proporcionar mais conforto. Para as mulheres que buscam sustentação, o ideal são as alças mais largas, mas para ocasiões especiais, elas podem usar uma alça mais fina, como essa, mais nadador, porque ela sustenta. Olha que decote mais lindo. Mais sexy com decote bonito. (Consultora; programa de 16/07/2013)

Na volta ao estúdio, o apresentador Fernando Rocha e o ginecologista José Bento retomam a matéria a que os telespectadores tinham acabado de assistir:

Você tem de experimentar, você tem de procurar um tecido de algodão porque o tecido sintético pode acabar machucando a pele, pode criar certas alergias à pele. Então, sempre procurar tecido feito de algodão e evitar aqueles aramados. Você pode usar, eventualmente. Numa festa, por exemplo. Mas continuamente, acaba machucando. Não tem nada a ver com câncer, mas acaba machucando. (José Bento, ginecologista; programa de 16/07/2013) 
Observemos os detalhes que a repórter vasculha (tipo de alça, tamanho do tronco e da taça, modelos que cobrem menos ou mais etc.) e, ao mostrar os diversos modelos de sutiã, legendas aparecem na tela lembrando ao telespectador a utilidade de cada um dos modelos ("laterais largas não deixam as gordurinhas aparecerem"; "sutiã reforçado diminui volume dos seios"; "seios grandes pedem alças mais largas" etc.). Repórter e consultora enfocam o lado estético do produto e as características que podem realçar atributos femininos, mas o ginecologista ressalta para a audiência que as qualidades mais importantes são o conforto e o tecido de algodão, pois este não causa alergias. Ou seja, o produto é enquadrado pelo especialista em termos de bem-estar. Destaquemos a performance dos sutiãs e lembremos que os médicos há muito têm tido uma função que ultrapassa a doença e a cura. "Os médicos assumiram sua função como peritos em estilo de vida", escreveu Nikolas Rose ${ }^{47}$.

\section{Aprendi com o Bem Estar}

Há um quadro no programa com o nome acima e nele o telespectador ganha a cena. Os mais emotivos, em geral, relacionam-se ao câncer e pela nossa observação são mais mencionados o de pele e o de intestinoxiii. A audiência é fisgada pela emoção e o sentimento de empatia, de se colocar no lugar do outro, vincula-a à temática. O quadro envolve também outros assuntos, como regularizar o intestino graças às dicas de alimentação (29/08/2012) ou como dormir na posição adequada (05/02/2014).

Verifiquemos uma edição sobre mudanças nos hábitos alimentares e atividade física, a temática mais frequente no quadro Aprendi com o Bem Estar - o que reflete e reforça a tônica do programa de que o estilo de vida "correto" é suficiente para uma vida saudável e longeva. Em 13/o1/2012, prestes a completar um ano, o programa exibiu três personagens que mudaram sua rotina, alimentação e peso graças ao Bem Estar. Daniela, em e-mail enviado ao programa, escreveu que perdera 44 quilos. Moradora de Santa Luzia (MG), ela não foi entrevistada, mas fotografias testemunharam sua transformação. O mesmo recurso foi utilizado para Danilo, de Cuiabá (MT), que emagrecera 19 quilos, ajudado pelos conselhos do programa e também por médicos que ele procurou. As duas histórias foram contadas utilizando-se das técnicas de antes e depois que, segundo Stephannie Roy ${ }^{48}$, contribuem para a criação de normas em relação às quais os indivíduos são julgados e vigiam a si próprios:

E aí ela [Daniela] aprendeu que não devia fazer dieta que o seu corpo não aguentasse e então resolveu fazer uma reeducação alimentar. Ela conseguiu emagrecer com saúde e segurança. Ela escreveu: como diz o Dr. Alfredo, não podemos dizer que perdemos peso, senão a gente recupera [Mariana, apresentadora]. É bonito isso, não é?! Saber que a gente transmite essas informações é muito bonito. (Alfredo Halpern, endocrinologista, programa de 13/1/2012)

Ao se autolegitimar como um programa sério, capaz de transformar as pessoas, o Bem Estar, por meio do endocrinologista no exemplo acima, se posiciona como autoridade no assunto capaz de fornecer ferramentas e técnicas para que o telespectador governe-se por si mesmo. Reinvindicar a expertise é uma estratégia sutil e constante. É como se os apresentadores e especialistas se autolegitimassem e dissessem: assistam às aulas do Bem Estar! Elas ensinam e ajudam as pessoas.

A terceira personagem dessa edição (13/1/2012), a representante comercial Mara, passou a fazer exercícios e também mudou a alimentação depois que começou a assistir ao Bem Estar. Em dez meses, ela emagrecera oito quilos. "Foi um exemplo para a minha casa, para a minha família. Tenho uma irmã que está no mesmo ritmo" (Mara, programa de 13/1/2012). Ela estende os benefícios dos novos hábitos a familiares e a parentes, o que expressa uma das missões do programa de ser útil à telespectadora e à sua famíla. Mara

xiii Entre 29/08/2012 e 08/03/2016 foram publicadas 27 edições do Aprendi com o Bem Estar, segundo sua página na internet. Entre os assuntos, estão exercícios e alimentação; alergia, primeiros socorros, cânceres etc. Vídeos disponíveis em: http://g1.globo.com/ bemestar/videos/aprendi-com-bem-estar Acesso em: 10 mar. 2016. 
é mostrada no percurso que faz a pé entre a sua casa e a academia, mas o repórter enfatiza que ela começou os exercícios nos degraus da sua casa e, então, são exibidas cenas de um programa em que o consultor e preparador físico, D’Elia, dá essa dica. Na volta ao estúdio, mais uma vez o especialista reforça essa atitude:

Ela tá na academia fazendo os exercícios. Mas o que eu gostei foi o subir e descer escadas. Qualquer pessoa, qualquer pessoa, pode fazer um tipo de atividade física. O subir e descer escada é um exemplo. Mas pode andar, pode parar dois pontos antes de onde vai trabalhar, pode estacionar o carro mais longe e ir a pé... Às vezes eu tenho medo de que as pessoas pensem que tem de ser atividade física na academia. Não, qualquer atividade física é atividade física. Existem umas melhores, outras piores, mas mexa-se. (Alfredo Halpern, endocrinologista, programa de 13/01/2012)

Se é tão fácil fazer atividade física - afinal, é possível fazê-la em qualquer lugar - trata-se o fato como essencialmente individual e de fácil correção e, dessa maneira, espalha-se o fenômeno da culpabilização da vítima $^{11}$ em que o indivíduo é o único responsável por suas ações e condições de vida ${ }^{\text {xiv }}$. Deborah Lupton ${ }^{49}$ reconhece que algumas pessoas vão simplesmente desobedecer tais conselhos. Outras, por sua vez, vão ter prazer em adotar essas recomendações no seu cotidiano, provavelmente, pela sensação de certeza, que pode advir diante de tantas informações sobre risco e insegurança. Dessa maneira, o quadro Aprendi com o Bem Estar evidencia a capacidade de agenciamento do programa ao mostrar personagens que mudaram de estilo de vida ou tiveram papel ativo na descoberta de alguma doença devido às informações do Bem Estar.

\section{Desempenhando as funções pastorais}

Os personagens que participam de shows de transformação também revelam histórias inspiradoras e didáticas e podem protagonizar reportagens de maneiras diversas. O ex-jogador Éder, personagem do quadro Bola pra Frente, foi acompanhado por psicólogo, nutricionista, educador físico e cardiologista, em Sinop (MT), com o objetivo de emagrecer 70 quilos entre o início de 2014 e fevereiro de 2015. Neste período, ele participou do Bem Estar, em edições diversas, contando suas conquistas e dificuldades. Na externa de 19/05/2014, Éder não fazia ginástica nem escolhia alimentos. Ele conversava com um grupo de crianças em um parque de Sinop (MT) sobre a importância da alimentação correta e da prática de exercícios. A atividade fazia parte da sua "missão" (palavras da repórter) de alertar estudantes de escolas públicas sobre os perigos da obesidade. Ao responder à pergunta de uma participante, Éder disse: "Eu engordei, Sara, porque eu fiquei em casa, não ajudava em nada; só comia e bebia. Trabalhava também, mas só trabalhos leves. Eu fiquei um cara sedentário." (Éder, ex-jogador de futebol, programa de 19/05/2014)

Seu depoimento lembra testemunhos bastante comuns em eventos religiosos em que a pessoa publicamente se penitencia dos erros e promete mudar de vida. Éder não estaria empregando a técnica do cristianismo de confessar, que é central para organizações religiosas e civis como técnica de produção da verdade 33 ? Não causa surpresa tal linguagem. No discurso terapêutico contemporâneo, há predomínio dos modos confessionais de comunicação ${ }^{50}$. Ao ensinar para as crianças, o Bem Estar também ensina para a audiência que Éder comeu muito, exagerou nas bebidas, não fez exercícios físicos e, por causa dos seus erros, está gordo e com colesterol alto etc.

Vale a pena apontarmos um aspecto que vai além do de educar nessa reportagem: ensinar para crianças na faixa de 9 a 12 anos tem um traço relevante pela possibilidade de diminuir a chance de uma puberdade obesa que poderia resultar em um obeso para o resto da vida, de acordo com o endocrinologista Alfredo Halpern, que elogia Éder ao comentar a reportagem no estúdio, naquela ocasião. Talvez pudéssemos dizer que esses quadros de transformação têm apenas a função de educar o telespectador como podem fazer

xiv Regina Lawrence ${ }^{51}$ encontrou reenquadramentos na imprensa norte-americana de aspectos como o próprio entendimento popular sobre a obesidade. Reconhecem-se, por exemplo, causas como redução de aulas de educação física nas escolas; falta de locais seguros para crianças brincarem ou adultos caminharem etc. 
o jornalismo tradicional e, nesse caso, consideraríamos os elementos do makeover show presentes no Bem Estar apenas uma renovação das estratégias de reportagem do jornalismo. No entanto, a produção do programa disponibiliza especialistas para tratar dos personagens das séries, quadros ou reality. $\mathrm{O}$ programa intervém ativamente para resolver um problema.

Assim, consideramos a ação educativa de Éder uma estratégia para reforçar a função social do programa e da própria emissora. É uma demonstração da tecnologia pastoral exercida pela TV Globo que se torna ainda mais visível nas edições do Bem Estar Global. Estas são realizadas ao ar livre em cidades brasileiras, normalmente às sextas (13/11/2015, em Campinas, nessa amostra). Nessas ocasiões, os jornalistasapresentadores comandam show de dança e/ou música e também as inserções de repórteres que, de tendas próximas ao palco, entram ao vivo para falar dos serviços de saúde oferecidos durante o evento. Em parceria com entidades de classe como a Sociedade Brasileira de Endocrinologia (SBE), a Sociedade Brasileira de Angiologia (SBA), a Sociedade Brasileira de Urologia (SBU), entre outras, o Bem Estar oferece serviços de avaliação e de orientação de saúde gratuitos para a população. Segundo o site da SBU, entidade que participou de todas as edições, cada Bem Estar Global tem cerca de seis a nove mil impactados ${ }^{\mathrm{xv}}$.

O Bem Estar Global está longe da estrutura do Projeto Criança Esperança ${ }^{x v i}$, mas perto se pensarmos em marketing de causas sociais. O evento oferece entretenimento aos que comparecem ao espaço público por meio dos cantores ou dançarinos que animam o espetáculo. Oferece também atendimento de saúde gratuito para a população em período que vai bem além dos 40 minutos do programa. Na gramática do gênero promocional televisivo, o Bem Estar Global destaca o produto, exaltando seus afazeres; agrada o telespectador, estreitando sua relação com ele; e valoriza a empresa, agregando atributos sociais à Rede Globo ${ }^{52}$.

No entanto, visto pela perspectiva que nos interessa neste artigo, disponibilizar profissionais para resolver problema de determinado grupo, no caso dos quadros para perda de peso, ou para orientar a comunidade das cidades em que se realiza o Bem Estar Global, não seria uma característica filantrópica do programa que estaria desempenhando as funções pastorais confiadas pelo Estado às instituições privadas $^{31}$ ? Na modernização do poder pastoral, cresce o número de "oficiais" desse poder, incluindo atores que não pertencem ao Estado ${ }^{31}$. É uma nova forma da televisão, enquanto tecnologia cultural, oferecer orientações pedagógicas para sua audiência de quem ela tenta moldar a conduta - são os especialistas em saúde que, com sua autoridade e discursos de verdade, acabam por serem referências pedagógicas para os telespectadores do Bem Estar. É dessa maneira, sem conexão óbvia com o mundo oficial, que o Estado neoliberal governa à distância.

\section{Considerações}

Cuidar da saúde tornou-se quase um imperativo moral ${ }^{11,53}$ e essa crença se reflete nos meios de comunicação que tendem a compreender como uma das suas missões tornar público assuntos de interesse coletivo $^{54}$. O Bem Estar aborda diariamente o tema e uma das maneiras de se endereçar à sua audiência é pelo modo instrucional que, de certa forma, perpassa todo o programa: ensinar de forma descontraída; revelar em imagens ou por meio de operadores didáticos processos que se sabe, mas nem sempre se vê; assentar-se em atos do cotidiano para que o telespectador possa gerenciar a sua vida e a da família por meio dos conselhos; demonstrá-los passo a passo em tutoriais e arrematá-los com dicas de forma a guiar e supostamente aumentar a capacidade dos indivíduos de desempenharem papel ativo na modelagem de um futuro incerto.

\footnotetext{
xv Entre janeiro e dezembro de 2015, o Bem Estar Global ocorreu em Florianópolis, Belo Horizonte, Belém, Vitória, Fortaleza, Campinas, Salvador.

xvi Projeto da Rede Globo que arrecada doações de telespectadores para investir em programas sociais no Brasil, em parceria com a Unesco, governo federal e outros.
} 
Argumentamos que a televisão tem a capacidade de governar informalmente no sentido do neologismo foucaultiano governamentalidade definido, de maneira geral, como a "condução da conduta" 29 . O poder não vem de um lugar centralizado, mas de uma multiplicidade de lugares para além das instituições formais do governo oficial como a mídia, órgãos públicos, autoridades econômicas, judiciárias, médicas, integrando uma rede que estaria em harmonia com aspirações de atores como empresas, grupos de pressão, famílias ou indivíduos.

Para tal, a televisão foi pensada como tecnologia cultural, ou seja, um recurso que ensina habilidades com destreza aos seus telespectadores por atuar na intimidade do lar e, no caso do Bem Estar, por estimulálos diariamente ao autoaperfeiçoamento e aos cuidados de si permanentes por meio dos especialistas. Maior evidência disso é o quadro Aprendi com o Bem Estar, que mostra testemunhos da audiência sobre o agenciamento que o programa provoca. As tecnologias de si, que o poder pastoral disponibilizou aos seres humanos individualizados, servem ao funcionamento pessoal de cada um no sentido de aumentar a potência do Estado ${ }^{55}$. O telespectador acaba governando si mesmo em nome da melhora da qualidade de vida; ele se torna desejoso de cuidar de si por meio da adoção de estilos saudáveis, estimulado pelo discurso dos especialistas. Como (quase) todos desejamos ser saudáveis, nem sempre percebemos que é por meio desse desejo legítimo que os profissionais de saúde, em nome desta, regulamentam a nossa vida privada.

\section{Referências}

1. Ortega F. O corpo incerto: corporeidade, tecnologias médicas e cultura contemporânea. Rio de Janeiro: Garamond; 2008.

2. Tabakman R. A saúde na mídia: medicina para jornalistas, jornalismo para médicos. São Paulo: Summus Editorial; 2013.

3. Medeiros F, Massarani L. A cobertura da gripe A (H1N1) 2009 pelo Fantástico. Rev Bras Ciênc Inf. [citado em 2013 mar. 3] 2011;34(1):41-59. Disponível em: http://www.scielo.br/pdf/interc/v34n1/a02v34n1

4. $\quad$ Ouellette L, Hay, J. Better living through reality TV: television and pos-welfare citizenship. Oxford: Blackwell Publishing; 2008.

5. Hall S. Da Diáspora: identidades e mediações culturais. Belo Horizonte: Ed. UFMG; 2009.

6. Moretti FA, Oliveira VE, Silva EMK. Acesso a informações de saúde na internet: uma questão de saúde pública? Rev Assoc Méd Bras. [citado em 2014 jul. 7] 2012;58(6):650-8. Disponível em: http://www. scielo.br/pdf/ramb/v58n6/v58n6a08.pdf

7. Ribeiro APG, Sacramento I, Roxo M, organizadores. A história da TV no Brasil: do início aos dias de hoje. São Paulo: Contexto; 2010.

8. Natansohn G. O corpo feminino como objeto médico e midiático. Estudos Feministas. [citado em 2013 jul. 13] 2005;13(2):287-304. Disponível em: http://www.scielo.br/scielo.php?script=sci arttext\&pid=S0104-026X2005000200004

9. Ferraretto EK. Do universo técnico-científico ao mundo do senso comum: estratégias comunicativas e representação sobre saúde no Dirário Gaúcho [dissertação]. Porto Alegre: UFRGS; 2006.

10. Mendonça O. Ciência no Globo Ciência. Psic Esc Educ. [citado em 2013 out. 8] 1996;1(1):45-52. Disponível em: http://pepsic.bvsalud.org/scielo.php?script=sci arttext\&pid=S1413-85571996000100007

11. Crawford R. Healthism and the medicalization of everyday life. Int J Heal Serv. 1980;10(3):365-87.

12. Moraes MRC. Autocuidado e gestão de si: hábitos saudáveis na mídia impressa nacional [tese]. São Paulo: USP; 2014.

13. Seale C. Media and Health. London: Sage Publications; 2002.

14. Natansohn G. Medicina, gênero e mídia: O programa Mulher da TV Globo. Est Fem. [citado em 2014 nov. 8] 2000;(8):46-63. Disponível em: https://periodicos.ufsc.br/index.php/ref/article/view/9855

15. Dubose M. Morality, complexity, experts and systems of authority in House, M.D. or "My big brain is my superpower". Television \& New Media. 2010;11(1):20-36. 
16. Bauman Z. O mal-estar da pós-modernidade. Rio de Janeiro: Jorge Zahar Ed; 1998.

17. Bortoliero S. Saberes profissionais compartilhados: o diálogo entre jornalistas e especialistas da saúde na tv cultura. Campo Grande: Intercom - Sociedade Brasileira de Estudos Interdisciplinares da Comunicação. [citado em 2014 nov. 22] 2001. Disponível em http://www.intercom.org.br/papers/ nacionais/2001/papers/NP9BORTOLIERO.PDF

18. Lewis T, Martin F, Sun W. Lifestyling Asia? Shaping modernity and selfhood on life-advice programming. International Journal of Cultural Studies. 2012;15(6):537-66.

19. Hill A. Audiences and popular factual television. London: Routledge; 2005.

20. Raisborough J. Being scrooge-like: an introduction to lifestyle media and the formation of the self. Lifestyle media and the formation of the self. London: Palgrave Macmillan; 2011:1-24.

21. Binkley S. Governamentality and lifestyle studies. Soc Comp. 2007;1(1):111-26.

22. Palmer G. Introduction: governancy and documentary. Discipline and liberty: television and governance. Manchester: Manchester University Press; 2003:1-20.

23. Bell D, Hollows J, editores. Ordinary lifestyles: popular media, consumption and taste. Maidenhead: Open University Press; 2005.

24. Taylor L. From ways of life to lifestyle: the 'ordinary-ization' of British gardening lifestyle television. E J Comm. 2002;17(4):479-93.

25. Ryan M. Entertaining fantasies: lifestyle and social life in 1980s America. J Comm Inq. 2015;39(1):82101.

26. Mittell J. A cultural approach to television genre theory. Cin J. 2001;40(3):1-24.

27. Hanusch F, Hanitzsch T. Mediating orientation and self-expression in the world of consumption: Australian and German lifestyle journalists' professional views. Med Cult Soc. 2013;35(8):943-59.

28. Foucault M. Governmentality. In: Burchell G, Gordon C, Miller P. The Foucault effect: studies in governmentality with two lectures by and an interview with Michel Foucault. Chicago: University of Chicago Press; 1991:87-104.

29. Gordon C. Governmental rationality: an introduction. In: Burchell G, Gordon C, Miller P. The Foucault effect: studies in governmentality with two lectures by and an interview with Michel Foucault. Chicago: University of Chicago Press; 1991:1-51.

30. Rose N. Government, authority and expertise in advanced liberalism. Eco Soc. 1993;22(3):283-99.

31. Foucault M. O sujeito e o poder. In: Dreyfus H, Rabinow P. Michel Foucault, uma trajetória filosófica para além do estruturalismo e da hermenêutica. Rio de Janeiro: Forense Universitário; 1995:231-249.

32. Emboava M, Rocha SM. Peritos do estilo de vida: transformando atitudes do telespectador do Bem Estar. Front: est mid. [citado em 2017 fev. 4] 2016;18(3):365-76. Disponível em: http://revistas.unisinos.br/ index.php/fronteiras/article/view/fem.2016.183.11/5679

33. Foucault M. História da sexualidade 1: a vontade de saber. Rio de Janeiro: Edições Graal; 1988.

34. Foucault M. Technologies of the self. In: Martin $L$ et al. Technologies of the self: a seminar with Michel Foucault. Massachusetts: Cushing-Malloy; 1988:16-49.

35. Hamann T. Neoliberalismo, governamentalidade e ética. Ecopol [citado em 2013 dez. 4] 2012;3:99-133. Disponível em: https://revistas.pucsp.br/index.php/ecopolitica/article/view/12910

36. Rose N. The politics of life itself. Th Cult Soc. 2001;18(6):1-30.

37. Rocha S, Sant'ana G. Modos de endereçamento e gênero televisivo: proposta metodológica para análise da televisão como forma cultural. In: Braga JL, Lopes MIV, Martino LC. Pesquisa Empírica em Comunicação. São Paulo: Ed. Paulus; 2010.

38. Gomes I, organizadora. Gênero televisivo e modo de endereçamento no telejornalismo. Salvador: Edufba; 2011.

39. Morley D, Brunsdon C. The Nationwide Television Studies. London and New York: Routledge Taylor and Francis Group; 1999.

40. Hartley J. Understanding news. New York: Routledge; 1982. 
41. Fechine $Y$. Performance dos apresentadores dos telejornais: a construção do ethos. Fam. [citado em 2016 maio 2] 2008;15(36):69-76. Disponível em: http://revistaseletronicas.pucrs.br/ojs/index.php/ revistafamecos/article/view/4417

42. Silva FM. A conversação como estratégia de construção de programas jornalísticos televisivos [tese]. Salvador: UFBA; 2010.

43. Vizeu A. Construção social da realidade e operadores jornalísticos. Fam. [citado em 2016 abr. 2] 2004;111-8. Disponível em: http://revistaseletronicas.pucrs.br/ojs/index.php/revistafamecos/article/ view/6321

44. Bentes I. House M.D.: o monitoramento da vida, do crime e da doença na era da sua visualidade técnica. Mat. [citado em 2016 fev. 16] 2010;3(2):103-114. Disponível em: https://www.revistas.usp.br/ matrizes/article/view/38261

45. Solier I. TV dinners: culinary television, education and distinction. Cont: J Med Cult Stud. 2005; 19(4):465-81.

46. Lewis T. He needs do face his fears with these five queers: Queer Eye for the Straight Guy, makeover tv and the lifestyle expert. Tel New Med. 2007;8(4):285-311.

47. Rose N. A política da própria vida: biomedicina, poder e subjetividades no século XXI. São Paulo: Paulus; 2013.

48. Roy S. Taking charge of your health: discourses of responsibility in English-Canadian women's magazine. Soc Heal Ill. 2008;30(3):463-77.

49. Lupton D. Lay discourses and beliefs related to food risks: an Australian perspective. Soc Heal Ill. 2005; 27(4):448-67.

50. Sacramento I, Frumento E. O câncer nas biografias sobre José Alencar: a construção de um ethos heroico. Rev Front: est mid. [citado 2016 maio 5] 2015;17(3):374-85. Disponível em: http://revistas. unisinos.br/index.php/fronteiras/article/view/fem.2015.173.11

51. Lawrence R. Framing obesity: the evolution of news discourse on a public health issue. Press Pol. 2004; 9(3):56-75.

52. Castro MLD. A fala autorreferencial na televisão brasileira: estratégias e formatos. Rev Com [citado em 2015 mar. 6] 2012;1(10):78-93. Disponível em: http://www.revistacomunicacion.org/pdf/n10/ mesa1/007.A fala autorreferencial na televisao brasileira Estrategias e formatos.pdf

53. Vaz P. O sentido das notícias sobre saúde na cultura contemporânea. ECO-POS. [citado em 2014 jan. 13] 2007;10(1):107-19. Disponível em: https://revistas.ufrj.br/index.php/eco_pos/article/view/1044

54. Lerner K. Investigando o conceito de saúde no contexto do jornalismo: alguns desafios teóricos metodológicos. Intercom; Foz do Iguaçu: UNILA; 2016.

55. Barros II JR. Técnicas de si nos textos de Michel Foucault: a influência do poder pastoral. Cadernos IHU ideas. [citado em 2016 fev. 10] 2012;10(173):1-18. Disponível em: https://revistas.ufrj.br/index.php/ eco pos/article/view/1044https://revistas.ufrj.br/index.php/eco pos/article/view/1044 